\title{
Developments of a W-band Gyro-TWA for high PRF operation
}

\author{
W. He, C. R. Donaldson, L. Zhang, P. McElhinney, J. Garner, K. Ronald, \\ A. W. Cross and A. D. R. Phelps \\ Department of Physics, SUPA, University of Strathclyde, Glasgow, Scotland, UK, G4 0NG
}

\begin{abstract}
Latest developments of a gyrotron travelling wave amplifier (gyro-TWA) with a helically corrugated waveguide and a cusp electron gun for operation over a bandwidth of $90-100 \mathrm{GHz}$ at a high pulse repetition rate $(5 \mathrm{kHz})$ are presented. Performance upgrades of the input coupler, pulsed power system and beam collector with water-cooling capability were realized for the high power wide band gyro-TWA.
\end{abstract}

Keywords-Gyro-TWA; W-band amplifier; mm-wave amplifier; gyro-amplifier; wide band amplifier.

\section{INTRODUCTION}

$\mathrm{R}$ ecently gyro-devices in the form of both a gyrotron travelling wave amplifier (gyro-TWA) [1-3] and a gyrotron backward wave oscillator (gyro-BWO) [4-6] have been developed at the University of Strathclyde. The gyro-TWAs are highly efficient and suited to high frequency operation due to the fast-wave cyclotron resonance maser instability. A helically corrugated interaction region (HCIR) was used to generate an "ideal" eigenwave which has an almost constant value of group velocity over a wide frequency band in the region of small axial wave numbers [7]. This dispersion was then used to match the dispersion line of an electron cyclotron mode or its harmonics allowing broadband microwave amplification to be achieved in the gyro-TWA. The attractive advantages of high frequency, high power and wide instantaneous frequency bandwidth can enable a number of improvements in various applications including high resolution RADAR, plasma diagnostics, fast communications, electron spin resonance in conjunction with magnetic resonance and accurate material analysis based on terahertz spectroscopy. In this paper the latest developments and achieved results of a $\mathrm{W}$-band gyro-TWA are presented.

\section{EXPERIMENT}

The beam-wave interaction was driven by an axis-encircling electron beam which is ideal for harmonic operation of gyro-devices as the mode selectivity nature of such a beam requires that the harmonic number is equal to the azimuthal index of a waveguide mode for effective beam-wave coupling, Such an approach would reduce the possibility of parasitic oscillations. The axis-encircling electron beam can be generated by a cusp electron gun [8,9]. A number of components have been upgraded for high operation at a high pulse repetition rate (PRF) and their microwave properties were measured. These components include corrugated quasi-optical mode converter, broadband input coupler, broadband microwave window, HCIR and pulsed power system.
Additionally the beam collector was upgraded with water-cooling capability.

An output window [10], as shown in Fig. 1, was re-designed, manufactured and measured. The upgraded window had a reflection of $-27 \mathrm{~dB}$ which is a nearly 10 times improvement when compared with the previous output window.

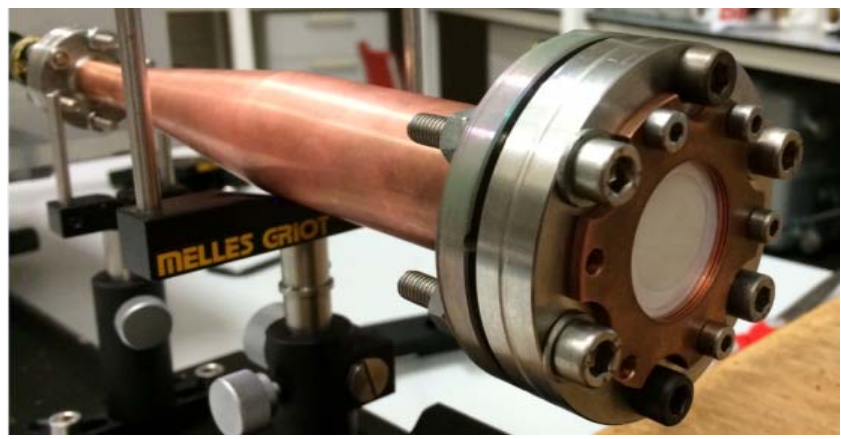

Fig. 1 A photo of the upgraded output window.

The input coupler [11] shown in Fig. 2 was also upgraded from its predecessor in a number of aspects. Its reflection was approximately $2 \mathrm{~dB}$ smaller, its achieved vacuum level was improved by a factor of 10 to $10^{-9} \mathrm{mbar}$ and it was mechanically stronger.

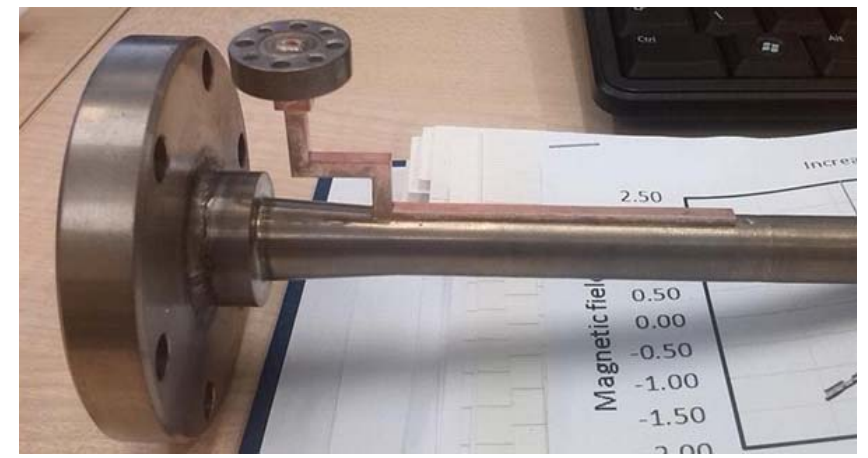

Fig. 2 A photo of the upgraded input coupler.

A beam collecting area was designed to allow cooling-water to be circulated and to accommodate the higher average power associated with an increased PRF. It was optimized through thermal simulations and manufactured as shown in Fig. 3. Also a novel pulsed power unit, as shown in Fig. 4, based on a thyratron as the closing switch has been designed and constructed and measured to be able to operate at a PRF of 2 $\mathrm{kHz}$. 


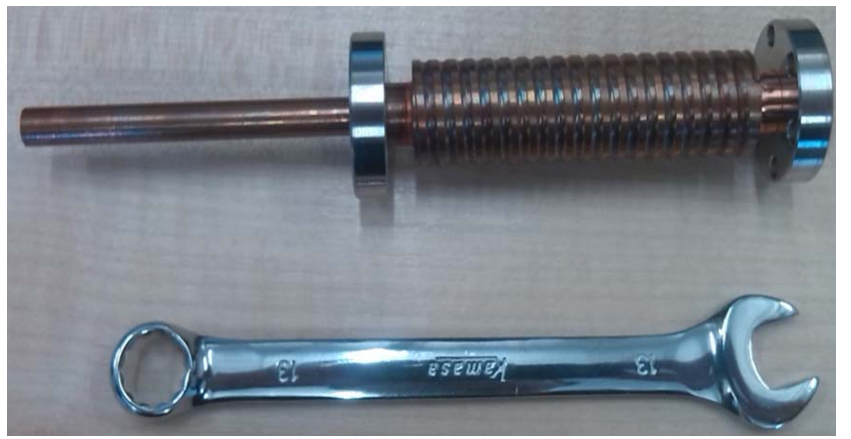

Fig. 3 A photo of water-cooled electron beam dump with a standard $13 \mathrm{~mm}$ spanner to provide an estimate of its size.

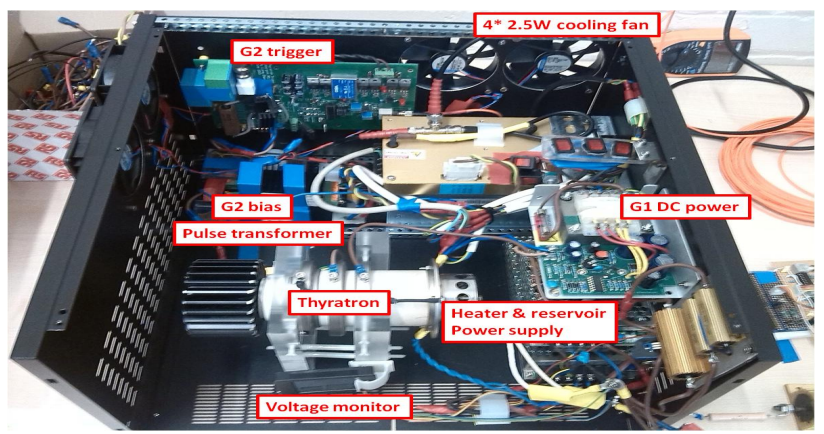

Fig. 4 A photo of thyratron based pulsed power unit.

The corrugated horn [12] was re-designed through numerical optimization and manufactured. The corrugated horn was used to output the amplified wave as well as allowing the recovery of the energy of the spent electron beam by using a depressed collector system [13]. The corrugated horn was also used as a mode converter for transforming a $\mathrm{TE}_{11}$ mode into the $\mathrm{TEM}_{00}$ fundamental free space mode over a frequency band of 90-100 $\mathrm{GHz}$. It was measured to have a reflection better than $-30 \mathrm{~dB}$ and a coupling efficiency of $\sim 99.4 \%$.

A pulsed power system in the form of a Blumlein network was used to accelerate the electron beam from the cusp gun. Fast electron beam current and voltage measurements with a rise time of 10-25 ns were achieved for time-correlated observation of the evolution of the pulse parameters. A beam current of typically $1.5 \mathrm{~A}$ was measured at the normal operating temperature of the thermionic cathode when a voltage pulse of $30-60 \mathrm{kV}$ with a pulse duration of $375 \mathrm{~ns}$ was applied. The output microwave radiation was detected by two crystal detectors situated inside screened boxes. The output power was calibrated using a solid state microwave source. The experimental results including the output powers and operating frequency bands were measured.

With an input seed signal from a $1.5 \mathrm{~W}, 90-96 \mathrm{GHz}$ solid state source a gain of $27 \mathrm{~dB}$ was measured from the experiment. The bandwidth was measured to be at least $5 \mathrm{GHz}$.

\section{SUMMARY}

A high power broadband W-band gyro-TWA has been experimentally measured. The measured results were in good agreement with theory and numerical simulations. The gyro-TWA was also upgraded to operate at a high PRF rate of 2 $\mathrm{kHz}$.

\section{ACKNOWLEDGMENTS}

The authors would like to thank EPSRC and STFC UK for supporting this work and Dr. P. Huggard, Mr M. Beardsley and Mr. P. Hiscock of the Millimetre Wave Technology Group at the STFC Rutherford Appleton Laboratory, UK for the construction of the HCIR.

\section{REFERENCES}

[1] A. W. Cross, W. He, A. D. R. Phelps, K. Ronald, C. G. Whyte, A. R. Young, C. W. Robertson, E. G. Rafferty, and J. Thomson, "Helically corrugated waveguide gyrotron traveling wave amplifier using a thermionic cathode electron gun,” Appl. Phys. Lett., vol. 90, (25), 253501, 2007.

[2] V. L. Bratman, A. W. Cross, G. G. Denisov, "High-gain wide-band gyrotron traveling wave amplifier with a helically corrugated waveguide," et al., Phys. Rev. Lett., vol. 84, pp. 2746-2749, 2000.

[3] G. G. Denisov, V. L. Bratman, A. W. Cross, et al., "Gyrotron traveling wave amplifier with a helical interaction region," Phys. Rev. Lett., vol. 81, pp. $5680-5683,1998$

[4] W. He, A. W. Cross, A. D. R. Phelps, K. Ronald, A. R. Young, C. G. Whyte, E. G. Rafferty, C. W. Robertson, J. Thomson, S. V. Samsonov, V. L. Bratman, and G. G. Denisov, "Theory and simulations of a gyrotron backward wave oscillator using a helical interaction waveguide", Appl. Phys. Lett., vol. 89, 091504, 2006.

[5] W. He, K. Ronald, A. R. Young, A. W. Cross, A. D. R. Phelps, C. G. Whyte, E. G. Rafferty, J. Thomson, C. W. Robertson, D. C. Spears, S. V. Samsonov, V. L. Bratman, G. G. Denisov, "Gyro-BWO experiments using a helical interaction waveguide", IEEE Trans. on Electron Devices, vol. 52, pp. 839-844, 2005.

[6] W. He, C. R. Donaldson, L. Zhang, K. Ronald, et al., "High power wideband gyrotron backward wave oscillator operating towards the terahertz region," Phys. Rev. Lett., vol. 110, 165101, 2013.

[7] L. Zhang, W. He, K. Ronald, A. D. R. Phelps, C. G. Whyte, C. W. Robertson, A. R. Young, C. R. Donaldson, and A. W. Cross, "Multi-mode coupling wave theory for helically corrugated waveguide," IEEE Trans. Microw. Theory Tech., vol. 60, pp. 1-7, 2012

[8] W. He, C. G. Whyte, E. G. Rafferty, A. W. Cross, A. D. R. Phelps, K. Ronald, A. R. Young, C. W. Robertson, D. C. Speirs, and D. H. Rowlands, "Axis-encircling electron beam generation using a smooth magnetic cusp for gyrodevices,” Appl. Phys. Lett., vol. 93, 121501, 2008.

[9] C. R. Donaldson, W. He, A. W. Cross, F. Li, A. D. R. Phelps, L. Zhang, K. Ronald, C. W. Robertson, C. G. Whyte and A. R. Young, "A cusp electron gun for millimeter wave gyro-devices," Appl. Phys. Lett., vol. 96, 141501, 2010.

[10] C. R. Donaldson, W. He, L. Zhang, and A. W. Cross, "A W-band multi-layer microwave window for pulsed operation of gyro-devices," IEEE Microw. Wireless Compon. Lett., vol. 23, pp. 237-239, 2013.

[11] L. Zhang, W. He, C. R. Donaldson, J. R. Garner, P. McElhinney, and A. W. Cross, "Design and Measurement of a Broadband Sidewall Coupler for a W-Band Gyro-TWA", IEEE Trans. Microw. Theory Tech., vol. 63, DOI 10.1109/TMTT.2015.2464302, (2015).

[12] P. McElhinney, C. R. Donaldson, L. Zhang, and W. He, "A high directivity broadband corrugated horn for W-band gyro-devices," IEEE Trans. Antennas Propag., vol. 61, pp. 1453-1456, 2013.

[13] L, Zhang., W. He, A. W. Cross, A. D. R. Phelps, K. Ronald \& C. G. Whyte, "Design of an Energy Recovery System for a Gyrotron Backward-Wave Oscillator". IEEE Transactions on Plasma Science, vol. 37, pp.390-394 (2009). 